\title{
Simultaneous portal and hepatic vein embolization before major liver resection
}

\author{
Jan Heil ${ }^{1,2} \cdot$ Erik Schadde $^{1,3,4} \mathbb{C}$
}

Received: 3 August 2020 / Accepted: 6 August 2020 / Published online: 24 August 2020

(C) The Author(s) 2020

\begin{abstract}
Background Regenerative liver surgery expands the limitations of technical resectability by increasing the future liver remnant (FLR) volume before extended resections in order to avoid posthepatectomy liver failure (PHLF). Portal vein rerouting with ligation of one branch of the portal vein bifurcation (PVL) or embolization (PVE) leads to a moderate liver volume increase over several weeks with a clinical dropout rate of $20-40 \%$, mostly due to tumor progression during the waiting period. Accelerated liver regeneration by the Associating Liver Partition and Portal vein Ligation for Staged hepatectomy (ALPPS) was poised to overcome this limitation by reduction of the waiting time, but failed due increased perioperative complications. Simultaneous portal and hepatic vein embolization (PVE/HVE) is a novel minimal invasive way to induce rapid liver growth without the need of two surgeries.

Purpose This article summarizes published results of PVE/HVE and analyzes what is known about its efficacy to achieve resection, safety, and the volume changes induced.

Conclusions PVE/HVE holds promise to induce accelerated liver regeneration in a similar safety profile to PVE. The demonstrated accelerated hypertrophy may increase resectability. Randomized trials will have to compare PVE/HVE and PVE to determine if PVE/ HVE is superior to PVE.
\end{abstract}

Keywords Liver $\cdot$ Hypertrophy $\cdot$ Future liver remnant $\cdot$ Liver regeneration $\cdot$ Portal vein embolization

\begin{tabular}{|c|c|c|c|c|}
\hline \multicolumn{3}{|c|}{ Abbreviations } & CRLM & Colorectal liver metastasis \\
\hline \multirow{2}{*}{\multicolumn{2}{|c|}{${ }^{99 \mathrm{~m}}$ Tc-mebrofenin HBS }} & Technetium-99 m hepatobiliary & CT & Computed tomography \\
\hline & & scintigraphy & $\mathrm{DH}$ & Degree of hypertrophy \\
\hline \multirow{3}{*}{\multicolumn{2}{|c|}{ ALPPS }} & Associating liver partition & eLVD & extended liver venous deprivation \\
\hline & & and portal vein ligation & FLR & Future liver remnant \\
\hline & & for staged hepatectomy & HVE & Hepatic vein embolization \\
\hline \multirow{2}{*}{\multicolumn{2}{|c|}{$\begin{array}{l}\text { AVP } \\
\text { cc }\end{array}$}} & Amplatzer vascular plug & HQPVE & High-quality portal vein \\
\hline & & Cubic centimeter & & embolization \\
\hline & & & $\mathrm{IHCC}$ & Intrahepatic cholonagiocarcinoma \\
\hline \multirow{3}{*}{\multicolumn{3}{|c|}{$\begin{array}{l}\text { Erik Schadde } \\
\text { erik.schadde@uzh.ch }\end{array}$}} & & Surgery \\
\hline & & & KGR & Kinetic growth rate \\
\hline & & & LVD & Liver venous deprivation \\
\hline \multirow{4}{*}{2} & \multicolumn{2}{|c|}{$\begin{array}{l}\text { Institute of Physiology, University of Zurich, Winterthurerstr. 190, } \\
\text { CH-8057 Zurich, Switzerland }\end{array}$} & NBCA/lipiodol & $\begin{array}{l}\text { N-Butyl-cyanoacrylate and } \\
\text { iodized oil }\end{array}$ \\
\hline & \multirow{2}{*}{\multicolumn{2}{|c|}{$\begin{array}{l}\text { Department of General, Visceral and Transplant Surgery, University } \\
\text { Hospital Frankfurt, Goethe-University Frankfurt, }\end{array}$}} & NET & Neuroendocrine tumor \\
\hline & & & PHCC & Perihilar cholangiocarcinoma \\
\hline & \multirow{2}{*}{\multicolumn{2}{|c|}{$\begin{array}{l}\text { Department of Surgery, Cantonal Hospital Winterthur, } \\
\text { Zurich. Switzerland }\end{array}$}} & PHLF & Posthepatectomy liver failure \\
\hline \multirow{2}{*}{3} & & & PVE & Portal vein embolization \\
\hline & & & PVL & Portal vein ligation \\
\hline 4 & $\begin{array}{l}\text { Department of Surgery, } \\
\text { Chicago, IL, USA }\end{array}$ & ush University Mledical Center Chicago, & $\mathrm{RCT}$ & Randomized controlled trial \\
\hline
\end{tabular}


SD

SFLR

TSH

\section{Introduction}

Regenerative liver surgery encompasses methods to increase the future liver remnant (FLR) before resection to expand the limitations of technical resectability of liver tumors. In the 1980s, Kinoshita et al. [1] discovered portal vein embolization (PVE) to protect the liver from tumor thrombi arising from hepatocellular carcinoma, and Makuuchi et al. [2] proposed PVE to allow resections in patients with primary liver tumors with small liver remnants. A Memorial Sloan-Kettering analysis of 1803 patients first showed that the number of resected liver segments had a higher impact on complications after liver resection than the complexity of the performed surgery (bile duct reconstruction, etc.) [3]. Beyond its impact on blood loss, the number of resected liver segments was the main predictive variate for morbidity and mortality and yielded a nearly linear association between the number of resected liver segments and complications. Later analyses confirmed that remnant volume is the main determinant of liver resection outcome [4].

With the advent of routine computed tomography (CT) volumetry, the focus shifted from the resected liver mass to the remaining liver volume [5]. The standardized future liver remnant (sFLR) was proposed for a more accurate estimation of the volume requirement after resection. In SFLR, the total liver volume is estimated by biometric data (body surface area or body weight) which excludes confounders as tumor volumes or dilated bile ducts and keeps the denominator stable when growth is assessed over multiple scans [6]. After systematic studies by the MD Anderson group, a minimal required sFLR of 20-30\% became the generally accepted cutoff for healthy livers and $\geq 40 \%$ in patients with abnormal histology like cirrhosis in order to avoid posthepatectomy liver failure (PHLF) $[4,5,7,8]$. To obtain volumes beyond this cutoff, PVE is used to increase the remnant volume with a moderate growth over several weeks [9]. A randomized study of patients undergoing PVE vs. no PVE prior to major hepatectomy was only performed in one study [10]. However, no strict volumetric criteria existed for inclusion; patients were included with and without cirrhosis and with mixed tumor types. In this study, only cirrhotic patients showed a reduction in complications with PVE, but patients with normal livers did not profit from routine PVE prior to major hepatectomy. A randomized study of PVE vs. no intervention in patients with a sFLR $<20-30 \%$ however appears unethical today due to the risk of PHLF and perioperative death and therefore convincing controlled clinical data are lacking for regenerative liver surgery in general.
In recent years, strategies different from PVE have been proposed to increase the sFLR prior to resection. Since volume enhancement is frequently desired in liver resections in two stages, Aussilhou et al. [11] showed that PVL used in twostaged hepatectomies (TSH) is equivalent to PVE in terms of its effect to make the liver grow. Kishi et al. [12] showed that adding a segment 4 embolization to PVE enhances the effect and developed the concept of high-quality PVE (HQPVE) over the last years. In 2012, the novel "Associating Liver Partition and Portal vein Ligation for Staged hepatectomy" (ALPPS) technique [13] demonstrated that hypertrophy after portal vein occlusion can be as extensive and fast as regeneration after partial hepatectomy itself, if a parenchymal transection is added to the portal vein ligation (PVL) during the first stage of the TSH. [14] In 2016, Guiu et al. [15] presented a novel interventional technique to induce rapid hypertrophy, the liver venous deprivation technique (LVD). In LVD, the hepatic in- and outflow of the right hemiliver are simultaneously occluded by using PVE and Amplatzer Vascular Plugs for the hepatic veins (AVP, Abott Vascular, formerly St. Jude Medical). This new technique increased liver regeneration comparable in scale and speed with ALPPS.

This review summarizes the current knowledge about the new method of simultaneous portal and hepatic vein embolization (PVE/HVE), a kind of "turbo"-PVE, and investigates its potential as yet another recent innovation in regenerative liver surgery.

\section{Portal vein rerouting and two-stage hepatectomies}

Both PVE and PVL allow to resect large or multiple tumors when more than $70 \%$ of the liver needs to be removed [16]. The main drawback of these approaches is the relative small effect on liver regeneration resulting in a drop-off rate of 20 $30 \%$, mostly due to tumor progression, partially bit also due to failure to grow $[9,17]$. While PVE is used either in conjunction with a TSH or not, PVL builds on the concept of TSH. TSH was initially described for multifocal colorectal liver metastasis (CRLM) [18] and later also for neuroendocrine tumor metastases [19]. During a first stage the main tumor mass was resected and then in a second stage, after a median of 4 months (3-7.5), the remaining tumor was resected [18]. The initial intent of the two stages was to reduce the risk of a simultaneous resection of liver metastases in both hemilivers by allowing recovery of the patient and the liver before a second repeat hepatectomy. Only in 6 of 16 cases in this seminal study, the surgeons additionally performed embolization to increase the liver remnant prior to the second stage [18]. In 2003, Kianmanesh et al. [19] demonstrated an entire series of TSHs using PVL during the first stage in every case after cleaning of the FLR (usually the left hemiliver) followed after a median of 6 weeks (4-8) by a right hepatectomy after an adequate 
hypertrophy was achieved. In contrast to the TSH that Adam et al. [18] had described, the two procedures followed each other rather rapidly, and generally the main tumor mass was resected with the right liver during the second stage [19].

In 2012, Schnitzbauer et al. [13] presented a technically novel type of TSH under the name of "in-situ-split hepatectomy", which was subsequently baptized as ALPPS in an Editorial by Clavien et al. [20]. In ALPPS, the TSH with PVL was combined with a transection of the liver parenchyma (in-situ-split) to allow resection of borderline resectable liver tumors after a median of only 9 days [13]. The new method increased hypertrophy and found a lot of enthusiastic follower, but was also criticized for its excessively high complication rates in some of its pioneering centers [21, 22]. The novel phenomenon of rapid hypertrophy was welcomed by many since it allowed faster resection and extended the limitation of technical resectability [23]. However, ALPPS remains tied to the concept of performing bilobar resections in two stages. Using ALPPS for tumors like perihilar cholangiocarcinoma (PHCC) or large unilobular tumors conceptually made no sense, since patient with hilar tumors and large masses should really only undergo one operation [21]. ALPPS therefore, as a clinical routine for all situations of borderline resectability, remained a highly controversial and - despite all the hypemarginally used technique [24].

\section{Simultaneous portal and hepatic vein embolization}

Since the first publication of LVD in 2016 by Guiu et al. [15], 7 more original studies have been published about PVE/HVE resulting in 8 series overall. Three of these are case series [15, 25, 26], and 5 are comparative studies (Table 1) [27-31]. In addition, a systematic review was published about portal and hepatic embolization including staged and simultaneous approaches, fairly early given the relative paucity of original data at the time point of its publication [32].

The number of patients included in all reports ranges between 6 [27] and 37 patients [31], yielding a total of 132 patients who underwent PVE/HVE in the published experience so far [15, 25-31]. Seven of 8 series included both primary and secondary liver tumors $[15,25,26,28-31]$. The most common tumor type was CRLM (55\% of all reported patients). One comparative study reported the experience of $\mathrm{PVE} / \mathrm{HVE}$ in PHCC alone [27].

\section{Technical aspects of PVE/HVE}

Guiu et al. [15, 25] called his technique a "deprivation of liver veins", because he did not only place AVPs in the larger hepatic veins, but also filled the smaller contributories with a mixture of $\mathrm{N}$-butyl-cyanoacrylate and iodized oil
(NBCA/lipiodol). In LVD, the right portal vein is embolized - without segment 4 embolization-and during the same session, the right hepatic vein is occluded by the use of AVPs followed with the addition liquid embolization with NBCA/lipidol of the small hepatic veins flowing to the AVPs. In a technically impressive and perfectionist approach, even visible venous collaterals that arise even during the procedure are embolized. In the subsequent article, Guiu et al. [25] then demonstrated a modified version of the LVD, the so-called extend liver venous deprivation (eLVD). eLVD provides an additional occlusion of the right middle hepatic vein using AVPs and NBCA/lipiodol. The eLVD technique, a "turbo" version of LVD in terms of hypertrophy was used in 4 further published series in a limited number of cases (Table 1) [26, 29-31]. Impressively, the Montpellier LVD technique is already being tested in an ongoing randomized controlled trail (RCT) of 8 centers in France (NCT03995459). However, the majority of published articles, which are not from the Montpellier group, except one article from Bordeaux, [31] did not use the additive liquid embolization of hepatic veins following AVP occlusion, but only placed AVPs without much attention to the small veins flowing to the AVPs (Table 1) [26, 27, 29, 30]. Also, the Montpellier group used a transhepatic approach for the hepatic vein embolization [15, $25,28]$, which has also been adopted by the Bordeaux group [31]. All other groups use the more common transjugular approach as their standard method $[26,27,29,30]$.

Two studies proposed the new name "bi-embolization" to their version of PVE/HVE performed without liquid embolization of smaller contributories [26, 30]. In contrast, the Lausanne group calls their approach "LVD", while they did not actually use liquid embolization. In certain sense, "LVD" for procedures without liquid embolization is a misnomer [29]. The Bordeaux group in contrast actually used an additional liquid embolization like the LVD technique and should have called their technique "LVD", but unfortunately created yet another name, "RASPE" (radiological simultaneous portohepatic vein embolization) [31].

In a Delphi process leading to the collaborative Dragon trial (DRAGON: NCT04272931), a decision among participating centers was made to refrain from the additional liquid embolization of small contributories due to the perceived risk of liquid embolization of the venous system, the right heart circulation and the lungs. Figure 1 shows a CT scan of a patient using multiple AVPs for right-sided hepatic vein embolization. However, to avoid further confusion, the generic descriptive PVE/HVE was used for the procedure.

\section{Feasibility of resection after PVE/HVE}

Taking all published series into account, 132 patients underwent PVE/HVE to increase the FLR prior to surgery $[15,25-31]$. Mean or median time between PVE/HVE and 
Table 1 Study designs and outcomes of embolization procedures after PVE/HVE

\begin{tabular}{|c|c|c|c|c|c|c|c|c|}
\hline Author & Year & Study design & Patients $n$ & $\begin{array}{l}\text { Type of tumor } \\
\text { (only PVE/HVE) }\end{array}$ & $\begin{array}{l}\text { HVE- } \\
\text { technique }\end{array}$ & $\begin{array}{l}\text { Embolized } \\
\text { hepatic vein }\end{array}$ & $\begin{array}{l}\text { Procedure-related } \\
\text { complications } n\end{array}$ & $\begin{array}{l}\text { Hospitals } \\
\text { stay }\end{array}$ \\
\hline Guiu et al. [15] & 2016 & Case series & PVE/HVE: 7 & $\begin{array}{l}\text { CRLM: } 2 \\
\text { HCC: } 1 \\
\text { IHCC: } 3 \\
\text { PHCC: } 1\end{array}$ & $\begin{array}{l}\text { Transhepatic } \\
\text { AVP } \\
+ \\
\text { NBCA/lipiodol }\end{array}$ & RHV: 7 & $\begin{array}{l}\text { Pain: } 5 \\
\text { Fever }>38^{\circ}: 5\end{array}$ & $\begin{array}{l}3 \text { days } \\
(2-5)\end{array}$ \\
\hline Guiu et al. [25] & 2017 & Case series & PVE/HVE: 10 & $\begin{array}{l}\text { CRLM: } 7 \\
\text { PHCC: } 1 \\
\text { Other: } 2\end{array}$ & $\begin{array}{l}\text { Transhepatic } \\
\text { AVP } \\
+ \\
\text { NBCA/lipiodol }\end{array}$ & RHV+MHV: 10 & $\begin{array}{l}\text { Asthenia } \\
\text { Grade 2: } 6 \\
\text { Grade 3: } 2 \\
\text { Pain: } 6 \\
\text { Fever > 38 : } 3\end{array}$ & $\begin{array}{l}3 \text { days } \\
(2-5)\end{array}$ \\
\hline $\begin{array}{l}\text { Le Roy et al. } \\
\text { [26] }\end{array}$ & 2017 & Case series & PVE/HVE: 7 & $\begin{array}{l}\text { CRLM: } 2 \\
\text { IHCC: } 1 \\
\text { PHCC: } 2 \\
\text { Other: } 2\end{array}$ & $\begin{array}{l}\text { Transjugular } \\
\text { AVP }\end{array}$ & $\begin{array}{l}\text { RHV: } 4 \\
\text { MHV: } 2 \\
\text { RHV+MHV: } 1\end{array}$ & 0 & n.r. \\
\hline $\begin{array}{l}\text { Hocquelet et al. } \\
\text { [27] }\end{array}$ & 2018 & $\begin{array}{l}\text { Comparative } \\
\text { study }\end{array}$ & $\begin{array}{l}\text { PVE/HVE: } 6 \\
\text { PVE: } 6\end{array}$ & PHCC: 6 & $\begin{array}{l}\text { Transjugular } \\
\text { AVP }\end{array}$ & RHV: 6 & 0 & $24-48 \mathrm{~h}$ \\
\hline Panaro et al. [28] & 2019 & $\begin{array}{l}\text { Comparative } \\
\text { study }\end{array}$ & $\begin{array}{l}\text { PVE/HVE: } 13 \\
\text { PVE: } 16\end{array}$ & $\begin{array}{l}\text { CRLM: } 10 \\
\text { HCC: } 3\end{array}$ & $\begin{array}{l}\text { Transhepatic } \\
\text { AVP } \\
+ \\
\text { NBCA/lipiodol }\end{array}$ & RHV: 13 & 0 & n.r. \\
\hline $\begin{array}{l}\text { Kobayashi et al. } \\
\text { [29] }\end{array}$ & 2020 & $\begin{array}{l}\text { Comparative } \\
\text { study }\end{array}$ & $\begin{array}{l}\text { PVE/HVE: } 21^{*} \\
\text { PVE: } 39\end{array}$ & $\begin{array}{l}\text { CRLM: } 10 \\
\text { HCC: } 2 \\
\text { PHCC: } 8\end{array}$ & $\begin{array}{l}\text { Transjugular } \\
\text { AVP }\end{array}$ & $\begin{array}{l}\text { RHV: } 18 \\
\text { RHV+MHV: } 2\end{array}$ & Hemobilia: 1 & n.r. \\
\hline $\begin{array}{l}\text { Le Roy et al. } \\
\text { [30] }\end{array}$ & 2020 & $\begin{array}{l}\text { Comparative } \\
\text { study }\end{array}$ & $\begin{array}{l}\text { PVE/HVE: } 31 \\
\text { PVE: } 41\end{array}$ & $\begin{array}{l}\text { CRLM: } 18 \\
\text { HCC: } 5 \\
\text { IHCC: } 2 \\
\text { PHCC: } 5 \\
\text { Other: } 1\end{array}$ & $\begin{array}{l}\text { Transjugular } \\
\text { AVP }\end{array}$ & $\begin{array}{l}\text { RHV: } 27 \\
\text { RHV+MHV: } 3 \\
\text { MHV: } 1\end{array}$ & 0 & 1 day \\
\hline $\begin{array}{l}\text { Laurent et al. } \\
\text { [31] }\end{array}$ & 2020 & $\begin{array}{l}\text { Comparative } \\
\text { study }\end{array}$ & $\begin{array}{l}\text { PVE/HVE: } 37^{+} \\
\text {PVE:36 }\end{array}$ & $\begin{array}{l}\text { CRLM:23 } \\
\text { IHCC: } 7 \\
\text { HCC: } 4 \\
\text { NET: } 2\end{array}$ & $\begin{array}{l}\text { Transjugular } \\
\text { AVP } \\
+ \\
\text { NBCA/lipiodol }\end{array}$ & $\begin{array}{l}\text { RHV: } 29 \text { RHV+ } \\
\text { MHV: } 8\end{array}$ & $\begin{array}{l}\text { Dindo-Clavien: } \\
\text { I: } 34 \\
\text { II: } 3\end{array}$ & $\begin{array}{l}1.4 \text { days } \\
(1-5)\end{array}$ \\
\hline
\end{tabular}

n.r not reported, AVP Amplatzer Vascular Plug, CRLM colorectal liver metastasis, HCC hepatocellular carcinoma, IHCC intrahepatic cholangiocarcinoma, $M H V$ middle hepatic vein, NBCA/lipiodol N-butyl-cyanoacrylate and iodized oil, $N E$ : neuroendocrine tumor, $P H C C$ perihilar cholangiocarcinoma, $P V E$ portal vein embolization, $P V E / H V E$ simultaneous portal and hepatic vein embolization, $R H V$ right hepatic vein

* Tumor type and information about the embolization were not given in one patient who failed to achieve liver resection

+ Tumor type of one patient was not given

surgery ranges between 21 [27] and 49 days (interquartile range (IQR) 20-210) [26], while one series did not report this time interval at all [30] (Table 2). During that interval, 16 patients developed progression of disease $[15,26,27$, 29-31], and in one patient, liver function growth was insufficient [25]. Overall, 115 of 132 patients (87\%) achieved surgical resection after PVE/HVE, resulting in a drop-off rate of $13 \%[15,25-31]$.

In the studies where PVE/HVE was compared with PVE, surgery was performed between a mean or median of 21 [27] to 45 days (standard deviation (SD) \pm 5 ) [31] after PVE, showing no difference between PVE/HVE and PVE (Table 4) [27-29, 31]. Again, one series did not report on that interval [30]. For PVE, resectability ranges between 76 [30] and 94\% [28]. In two comparative series, the feasibility of resection after PVE/HVE vs. PVE was not specifically analyzed due to the small study size $[27,28]$. However, in the remaining 3 comparative series, no difference was seen in resectability between both approaches [29-31].

The importance of the endpoint feasibility of resection to assess methods of regenerative liver surgery was recently demonstrated by the Scandinavian LIGRO trial (NCT02215577) - the first RCT of ALPPS vs. TSH [33]. Patients with borderline resectable CRLM were randomized either to ALPPS or TSH with a PVL during the first stage or a PVE between the stages. Patients included in this trial were highly selected and received induction chemotherapy. Both approaches, ALPPS and TSH demonstrated a relatively high morbidity (43\% major complications $(\geq \mathrm{IIIa}$ ) in both procedures) and high mortality (ALPPS: $9.1 \%$ vs. TSH: $10.7 \%$ ). However, patients who underwent ALPPS had a $92 \%$ vs. $57 \%$ (TSH) resectability $(p<0.001)$. While in the ALPPS cohort patients underwent both stages within a mean of 11 days (SD \pm 11 ), in the TSH cohort the second stage was performed after 


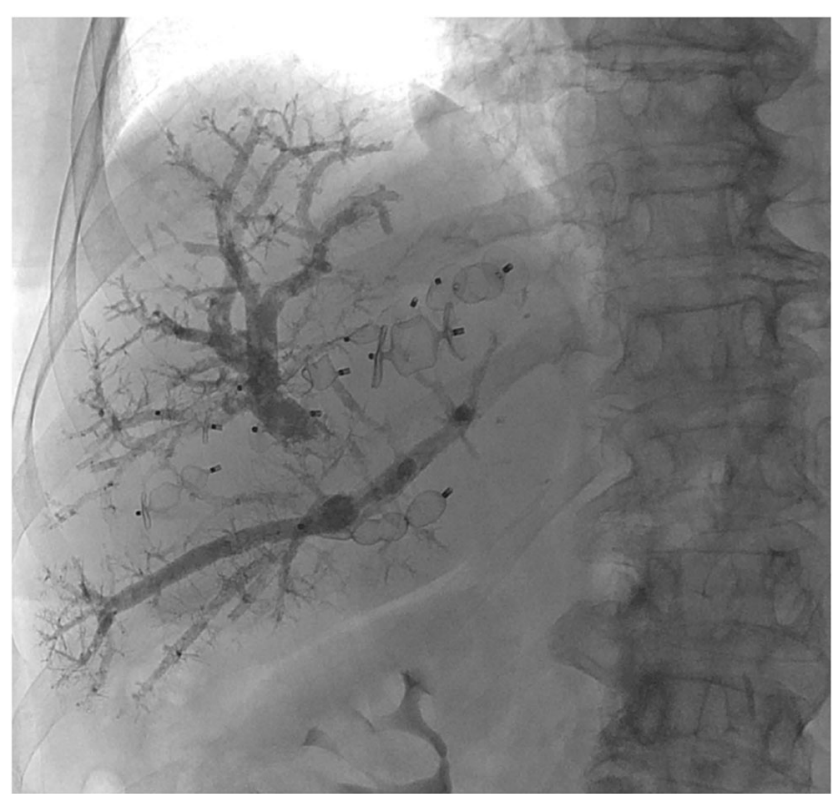

Fig. 1 CT scan of a patient using multiple AVPs for right-sided hepatic vein embolization

a mean of 43 days $(\mathrm{SD} \pm 15)$ due to the slower hypertrophy $(p<0.001)$. During that time, $16 \%$ in the TSH cohort had tumor progression, and $27 \%$ demonstrated insufficient liver growth. Interestingly, in a follow-up evaluation [34], the ALPPS cohort also demonstrated an improved median survival of 46 months compared with 26 months after TSH ( $p=$ $0.028)$. For the first time, the LIGRO trial demonstrated an effect of a surgical resection technique on survival in metastases surgery based on randomized data. It appears as if rapid resection of the entire tumor load in CRLM matters.

\section{Safety of PVE/HVE}

The interventional radiology procedure $\mathrm{PVE} / \mathrm{HVE}$ was successfully performed in all 132 patients in the published series, and no severe adverse events were reported (Table 1) [15, 25-31]. No difference of complications after the intervention itself was reported in the 5 comparative series between PVE/HVE and PVE [27-31]. Theoretical concerns about liver necrosis due to the simultaneous occlusion of the hepatic in- and outflow were not observed in these initial clinical reports [15]. As far as the effect of PVE/HVE on the liver is concerned, 8 days after LVD the transaminases remain slightly elevated, but there was no sign of liver necrosis in histology, which was confirmed by two further studies [28, 31]. It has to be assumed that the devascularized lobe remains viable by arterial blood flow alone [35]. It has to be postulated that new venous outflow collaterals enable the drainage of the arterial blood [36]. In any case, arterial blood flow appears sufficient to avoid liver necrosis at a larger scale.

\section{Postoperative outcome}

The majority of patients who underwent PVE/HVE as preparation later underwent a major hepatectomy (Table 2) [15, 25-30]. Seven of 8 series reported on the postoperative complications of this hepatectomy using the Dindo-Clavien classification [15, 25, 26, 28-31], while one comparative study did not provide information about the postoperative outcome according to the Dindo-Clavien classification [27]. In these 7 series, 111 patients underwent surgery after PVE/HVE [15, $25,26,28-31]$. Overall complications occurred in 75 of those (68\%), while complications at least III were reported in 23 patients $(21 \%)$. PHLF occurred in 5 patients $(5 \%)[27,28]$. In one series, 50-50 criteria were used of assessment [27], while the other studies defined PHLF according to the International Study Group of Liver Surgery (ISGLS) criteria [28].

All series except one [31] reported their mortality [15, 25-30], but two series did not mention if perioperative mortality rate referred to the 30 - or 90 -day mortality $[28,29]$. Of the 111 patients who underwent surgery after PVE/HVE, 5 patients died in the postoperative course, resulting in a mortality rate of $5 \%[15,26,30]$. One series reported that one of 6 patients died 10 days after surgery due to postoperative pneumonia [15]. In another study, one patient died 10 days after coiling of the common hepatic artery for postoperative hemorrhage [26]. No further information was provided on the death of 3 more patient within 90 days after resection [30].

When morbidity and mortality of PVE/HVE were compared with PVE in the comparative studies, no difference was observed between the two (Tables 2 and 4) [27-31]. However, one series demonstrated a difference in the occurrence of PHLF between PVE/HVE (0\%) and PVE (23\%) $(p=$ 0.012 ) [31].

Interestingly, all of these mortalities after both ALPPS and TSH were PHLF-related in the LIGRO trial [33]. Overall, 5 patients in all studies available so far developed PHLF following PVE/HVE (Table 2), but none of these cases resulted in a perioperative death $[15,26,30]$.

\section{Volumetric effect of PVE/HVE}

All series report on the volume increase of the FLR after PVE/ HVE (Table 3) [15, 25-31], but a comparison between the series is difficult due to the inhomogeneity of metrics used to measure liver volume and growth. A standardization should be considered obligatory for future studies.

Standardized volumetric data by the use of biometric formulas for the sFLR are only provided by two studies [25, 29]. In the series comparing PVE/HVE with PVE, no significant difference was achieved in the sFLR after the respective interventions (Tables 3 and 4) [29]. However, the achieved percent hypertrophy was significantly different of the FLR (35\% (IQR 


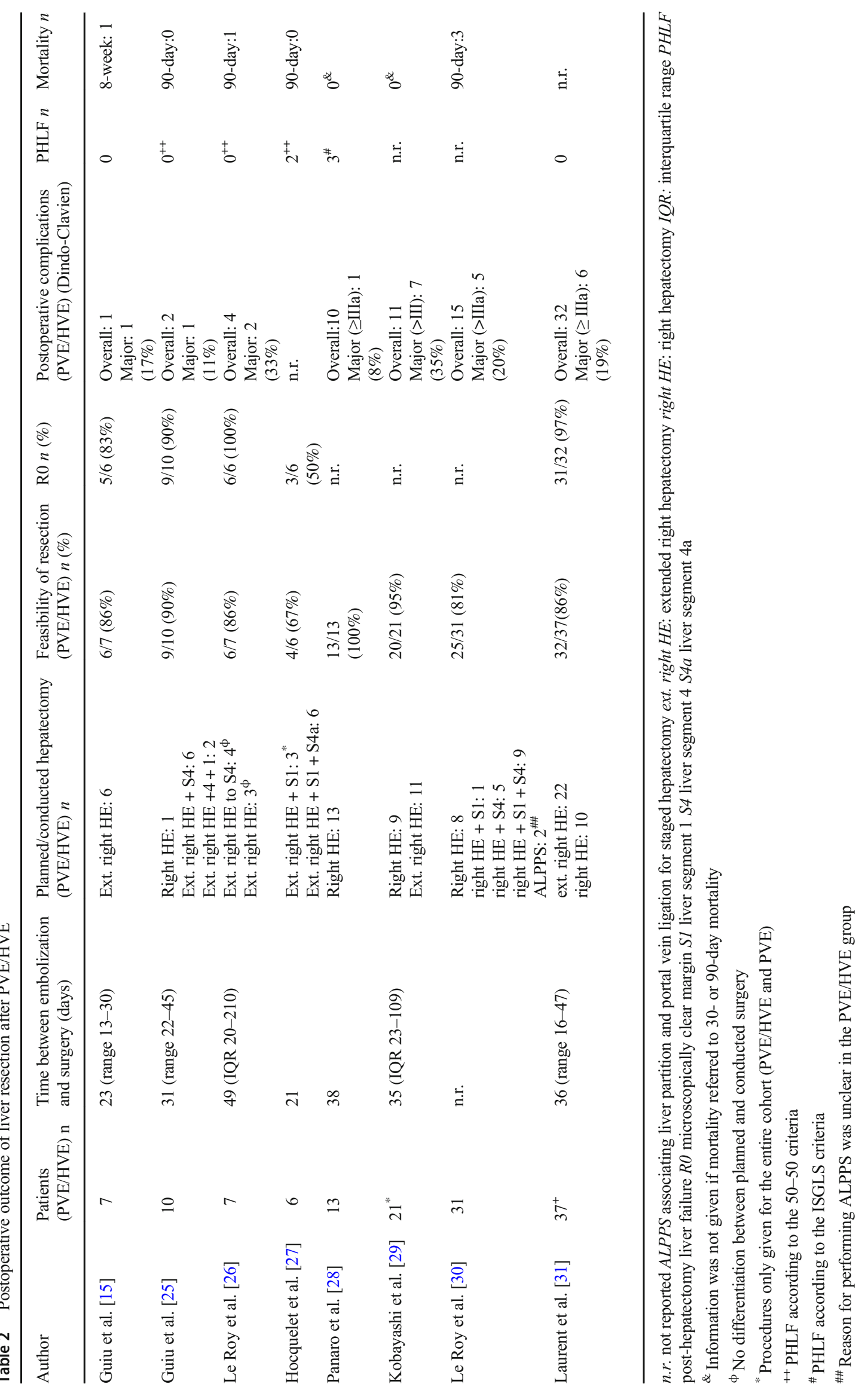




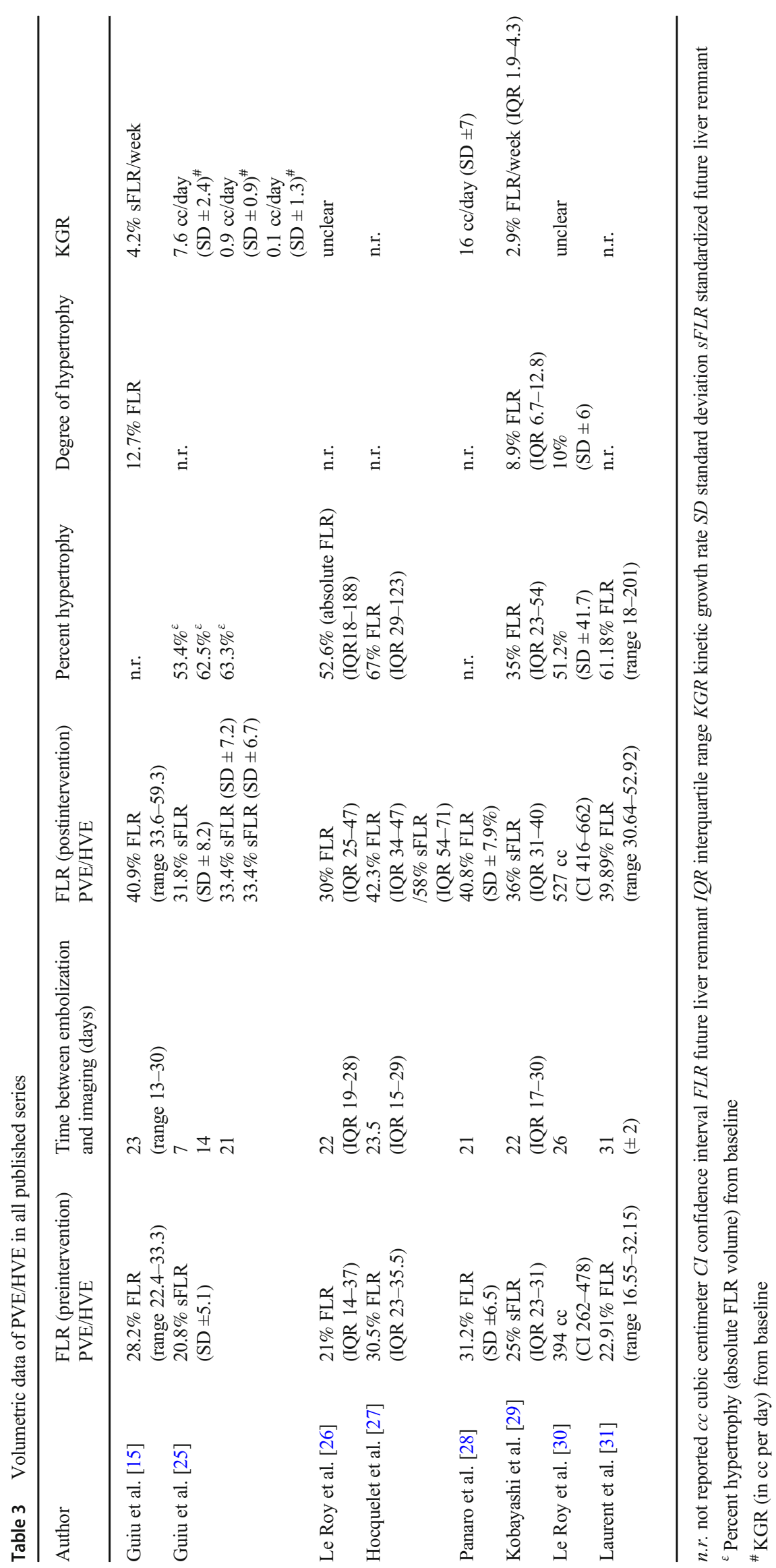




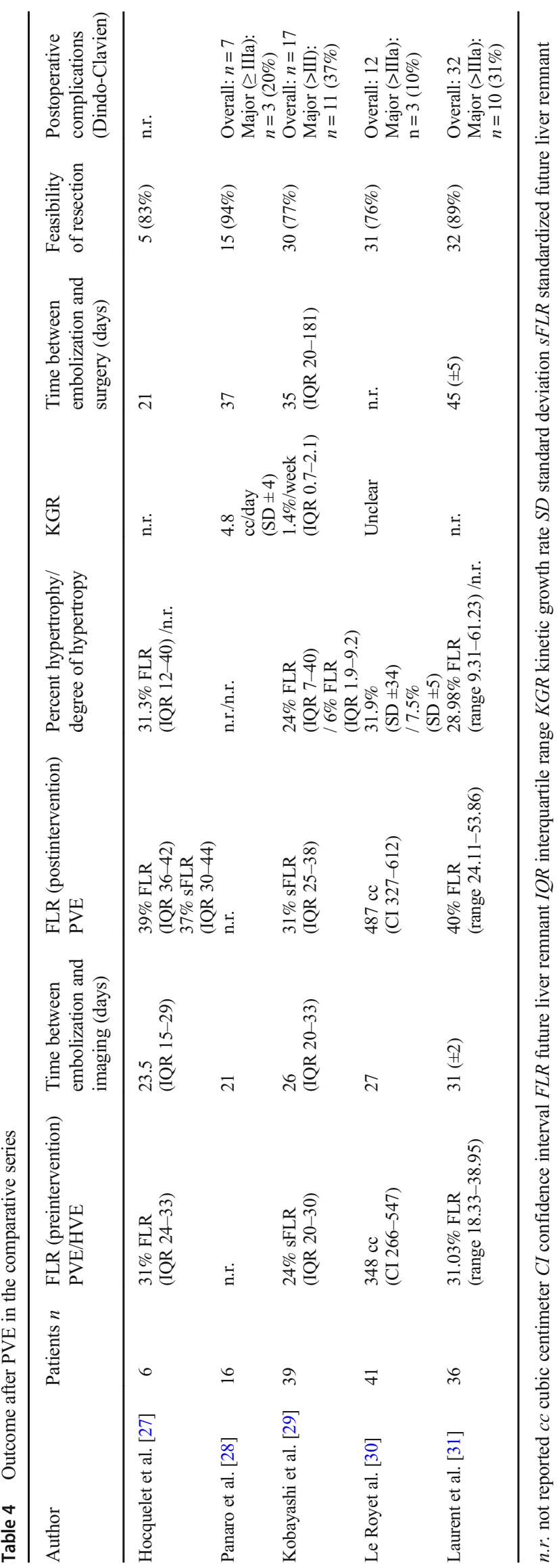

23-54) vs. $24 \%$ (IQR 7-40) resp. $p=0.03$ ). The same was shown by the comparative study from Clermont-Ferrand group [30], which unfortunately used the metrics "absolute FLR volume" in cubic centimeters (cc). While the liver volume did not differ after PVE/HVE and PVE, the percent hypertrophy (in cc) shows a significant difference: $51.2 \%$ (SD \pm $41.7)$ vs. $31.9 \%(\mathrm{SD} \pm 34)(p=0.018)$. The percent hypertrophy also differed between PVE/HVE and PVE in a recently published comparative series, but the starting FLR in the PVE control calls into question, if a regenerative maneuver was indicated in these patients at all [31].

To compare the novel PVE/HVE with PVE, the choice of the PVE control group really matters. The MD Anderson group has shown that PVE can be performed as low- or high-quality procedure [12]. In HQPVE, embolization segment 4 is added to right hemiliver embolization. Any new version of PVE like PVE/HVE has to be compared with HQPVE. In HQPVE, an increase of the sFLR of $20.1 \%$ (range: $9.5-57.8$ ) to $29.4 \%$ (range: $20.1-75.1$ ) within a median of 30 days should be considered to be the gold standard [37]. The same applies to the growth metrics "degree of hypertrophy (DH)", which is defined as the sFLR after the intervention minus the sFLR prior to the invention. The $\mathrm{DH}$ of 8.9\% (IQR 6.7-12.8) for PVE/HVE demonstrated by the Lausanne group [29] or the DH of $12.7 \%$ by the Montpellier group [15] have to be compared with $10.1 \%(0.1-39.9)$ after HQPVE as published by the MD Anderson group [37]. Unfortunately, the comparison is limited because the Lausanne [29] and Montpellier group [15] preferred to use FLRs instead of sFLR.

To estimate the speed of liver growth, the metrics "kinetic growth rate" (KGR) is routinely used, which is defined as the ratio between the $\mathrm{DH}$ and the elapsed time in weeks between embolization and first cross-sectional volumetry in sFLR/ week [37]. Unfortunately, 2 series did not give any information about the KGR [27, 31], and in 2 further series, the calculation of the KGR is unclear [26, 30]. Two used percent of total liver volume increase per week as their metrics for kinetic growth (Table 3) [25, 28].

While the initial study from Montpellier reported a KGR of $4.2 \%$ sFLR/week for PVE/HVE after a median of 23 days (range: 13-30) [15], the MD Anderson group gave a KGR of $2.4 \% \mathrm{sFLR} /$ week (range: 0.2-9.4) after a median of 30 days (range: 14-54) for PVE. Of note, 63\% of patients underwent HQPVE in this study. Although the KGR after PVE/HVE was two times higher in the Montpellier group than that of HQPVE, it should be noted that the volumetric assessment was performed 7 days later at the MD Anderson [37], which may introduce a bias towards a higher KGR. Also, none of the patients reported from Montpellier had diabetes or underwent chemo before embolization, [15] while the MD Anderson report included patients with diabetes $(6.8 \%)$ and chemotherapy (92.3\%), which is known to reduce the $\operatorname{KGR}[7,37,38]$. The 
Lausanne group demonstrates a KGR of $2.9 \%$ FLR/week (IQR 1.9-4.3) after a median of 22 days (IQR 17-30), while $50 \%$ of patients underwent chemotherapy [29].

The report by the Montpellier group about eLVD in 2017 reports a successive volume increase over 3 time points $(7,14$, and 21 days) in 3 patients [25]. From day 0 to day 7, the FLR increased from a mean of $20.8 \%$ $(\mathrm{SD} \pm 5.1)$ to a mean of $31.8 \%(\mathrm{SD} \pm 8.2)$ (53\% hypertrophy from baseline). From day 7 to day 14, the FLR increased less dramatically from 31.8 to $33.4 \%$ ( $\mathrm{SD} \pm 7$ ) (63\% hypertrophy from baseline) and from day 14 to 21 from 33.4 to $33.4 \%$ ( $\mathrm{SD} \pm 6.7$ ) (63\% hypertrophy from baseline). The Scandinavian LIGRO trial also reports volume data after 7 days [33]. The percent hypertrophy in $\mathrm{ml}$ in patients suffering from CRLM was $68 \%( \pm 38)$ for ALPPS and 43\% $( \pm 30)$ for PVE or PVL. Looking at these data, PVE/HVE seems to be right in the middle between PVE and ALPPS [25].

\section{Function data}

There is evidence that ALPPS leads to an incongruent increase in volume and function using technetium-99 m hepatobiliary scintigraphy $\left({ }^{99 \mathrm{~m}} \mathrm{Tc}-\mathrm{mebrofenin} \mathrm{HBS}\right)[39$, 40]. PVE/HVE has also been evaluated for functional changes using ${ }^{99 \mathrm{~m}} \mathrm{Tc}$-mebrofenin $\mathrm{HBS}$ in 10 patients [25]. In 3 of those, who underwent eLVD, a serial measurement was performed at days 7, 14, and 21 (according to the volume assessment). Although, these data are based on a small patient sample size, a parallel increase was described in volume and function with a maximal function already at day $7(65.7 \%(\mathrm{SD} \pm 16))$. Afterwards, at day 14 and 21, the function does not demonstrate a further increase from baseline (14 days: 57\% (SD \pm 18$)$ and 21 days: $57 \%( \pm 18)$.

\section{Limitations}

Overall studies about PVE/HVE are characterized by a small study size and highly selected patients. Patients with diabetes for example have been underrepresented $[30,37]$. Not more than 5 patients had liver cirrhosis, and only 6 patients had elevated bilirubin before embolization and needed a biliary drainage $[27,28,30]$. In 5 series, patients $(n=50)$ were reported to have received chemotherapy before embolization, but not all series provide information about the specific drugs used [25, $26,28,29,31]$.

The question if PVE/HVE has long-lasting advantages over PVE can likely not be answered by cohort studies, but requires a RCT. Currently two studies are registered (International DRAGON trial: NCT04272931, LVD France trial: NCT03995459).

\section{Conclusions}

Data from cohort studies demonstrate that PVE/HVE does not result in a higher rate of morbidity and mortality than PVE. It appears that induction of accelerated and more extensive hypertrophy increases resectability compared with PVE. Future RCTs will be able to determine, if PVE/HVE represents a true improvement over PVE.

Funding information Open access funding provided by University of Zurich. The author Jan Heil is supported by a grant from the Deutschen Forschungsgemeinschaft (DFG) (Project number Forschungsstipendium No. 423392184).

\section{Compliance with ethical standards}

Conflict of interest The authors declare that they have no conflict of interest.

Ethical approval This article does not contain any studies with animals performed by any of the authors or any studies with human participants performed by any of the authors.

Open Access This article is licensed under a Creative Commons Attribution 4.0 International License, which permits use, sharing, adaptation, distribution and reproduction in any medium or format, as long as you give appropriate credit to the original author(s) and the source, provide a link to the Creative Commons licence, and indicate if changes were made. The images or other third party material in this article are included in the article's Creative Commons licence, unless indicated otherwise in a credit line to the material. If material is not included in the article's Creative Commons licence and your intended use is not permitted by statutory regulation or exceeds the permitted use, you will need to obtain permission directly from the copyright holder. To view a copy of this licence, visit http://creativecommons.org/licenses/by/4.0/.

\section{References}

1. Kinoshita H, Sakai K, Hirohashi K, Igawa S, Yamasaki O, Kubo S (1986) Preoperative portal vein embolization for hepatocellular carcinoma. World J Surg 10:803-808

2. Makuuchi M, Takayasu K, Takuma T et al (1984) Preoperative transcath- eter embolization of the portal venous branch for patients receiving extended lobectomy due to the bile duct carcinoma. J Jpn Soc Clin Surg 45:14-21

3. Jarnagin WR, Gonen M, Fong Y, DeMatteo RP, Ben-Porat L, Little S, Corvera C, Weber S, Blumgart LH (2002) Improvement in perioperative outcome after hepatic resection: analysis of 1,803 consecutive cases over the past decade. Ann Surg 236(4):397-406 discussion 406-7

4. Kishi Y, Abdalla EK, Chun YS, Zorzi D, Madoff DC, Wallace MJ, Curley SA, Vauthey JN (2009) Three hundred and one consecutive extended right hepatectomies: evaluation of outcome based on systematic liver volumetry. Ann Surg 250(4):540-548

5. Vauthey JN, Chaoui A, Do KA, Bilimoria MM, Fenstermacher MJ, Charnsangavej C, Hicks M, Alsfasser G, Lauwers G, Hawkins IF, Caridi J (2000) Standardized measurement of the future liver remnant prior to extended liver resection: methodology and clinical associations. Surgery 127(5):512-519 
6. Vauthey JN, Abdalla EK, Doherty DA, Gertsch P, Fenstermacher MJ, Loyer EM, Lerut J, Materne R, Wang X, Encarnacion A, Herron D, Mathey C, Ferrari G, Charnsangavej C, Do KA, Denys A (2002) Body surface area and body weight predict total liver volume in Western adults. Liver Transpl 8(3):233-240

7. Shindoh J, Tzeng CWD, Aloia TA, Curley SA, Zimmitti G, Wei SH, Huang SY, Mahvash A, Gupta S, Wallace MJ, Vauthey JN (2013) Optimal future liver remnant in patients treated with extensive preoperative chemotherapy for colorectal liver metastases. Ann Surg Oncol 20(8):2493-2500

8. Truty MJ, Vauthey JN (2010) Uses and limitations of portal vein embolization for improving perioperative outcomes in hepatocellular carcinoma. Semin Oncol 37(2):102-109

9. van Lienden KP, van den Esschert JW, de Graaf W, Bipat S, Lameris JS, van Gulik TM, van Delden OM (2013) Portal vein embolization before liver resection: a systematic review. Cardiovasc Intervent Radiol 36(1):25-34

10. Farges O, Belghiti J, Kianmanesh R, Marc Regimbeau J, Santoro R, Vilgrain V, Denys A, Sauvanet A (2003) Portal vein embolization before right hepatectomy: prospective clinical trial. Ann Surg 237(2):208-217

11. Aussilhou B, Lesurtel M, Sauvanet A, Farges O, Dokmak S, Goasguen N, Sibert A, Vilgrain V, Belghiti J (2008) Right portal vein ligation is as efficient as portal vein embolization to induce hypertrophy of the left liver remnant. J Gastrointest Surg 12(2): 297-303

12. Kishi Y, Madoff DC, Abdalla EK, Palavecino M, Ribero D, Chun YS, Vauthey JN (2008) Is embolization of segment 4 portal veins before extended right hepatectomy justified? Surgery 144(5):744 751

13. Schnitzbauer AA, Lang SA, Goessmann H, Nadalin S, Baumgart J, Farkas SA, Fichtner-Feigl S, Lorf T, Goralcyk A, Hörbelt R, Kroemer A, Loss M, Rümmele P, Scherer MN, Padberg W, Königsrainer A, Lang H, Obed A, Schlitt HJ (2012) Right portal vein ligation combined with in situ splitting induces rapid left lateral liver lobe hypertrophy enabling 2-staged extended right hepatic resection in small-for-size settings. Ann Surg 255(3):405-414

14. Nadalin S, Testa G, Malagó M, Beste M, Frilling A, Schroeder T, Jochum C, Gerken G, Broelsch CE (2004) Volumetric and functional recovery of the liver after right hepatectomy for living donation. Liver Transpl 10(8):1024-1029

15. Guiu B, Chevallier P, Denys A, Delhom E, Pierredon-Foulongne MA, Rouanet P, Fabre JM, Quenet F, Herrero A, Panaro F, Baudin G, Ramos J (2016) Simultaneous trans-hepatic portal and hepatic vein embolization before major hepatectomy: the liver venous deprivation technique. Eur Radiol 26(12):4259-4267

16. Kawaguchi Y, Lillemoe HA, Vauthey JN (2019) Dealing with an insufficient future liver remnant: portal vein embolization and twostage hepatectomy. J Surg Oncol 119(5):594-603

17. Shindoh J, Tzeng CWD, Aloia TA, Curley SA, Huang SY, Mahvash A, Gupta S, Wallace MJ, Vauthey JN (2014) Safety and efficacy of portal vein embolization before planned major or extended hepatectomy: an institutional experience of 358 patients. J Gastrointest Surg 18(1):45-51

18. Adam R, Laurent A, Azoulay D, Castaing D, Bismuth H (2000) Two-stage hepatectomy: a planned strategy to treat irresectable liver tumors. Ann Surg 232(6):777-785

19. Kianmanesh R, Farges O, Abdalla EK, Sauvanet A, Ruszniewski P, Belghiti J (2003) Right portal vein ligation: a new planned two-step all-surgical approach for complete resection of primary gastrointestinal tumors with multiple bilateral liver metastases. J Am Coll Surg 197(1):164-170

20. de Santibanes E, Clavien PA (2012) Playing Play-Doh to prevent postoperative liver failure: the "ALPPS" approach. Ann Surg 255(3):415-417
21. Schadde E, Raptis DA, Schnitzbauer AA, Ardiles V, Tschuor C, Lesurtel M, Abdalla EK, Hernandez-Alejandro R, Jovine E, Machado M, Malago M, Robles-Campos R, Petrowsky H, Santibanes ED, Clavien PA (2015) Prediction of mortality after ALPPS stage-1: an analysis of 320 patients from the international ALPPS registry. Ann Surg 262(5):780-785 discussion 785-6

22. Schadde E, Ardiles V, Robles-Campos R, Malago M, Machado M, Hernandez-Alejandro R, Soubrane O, Schnitzbauer AA, Raptis D, Tschuor C, Petrowsky H, de Santibanes E, Clavien PA, ALPPS Registry Group (2014) Early survival and safety of ALPPS: first report of the International ALPPS Registry. Ann Surg 260(5):829836 discussion 836-8

23. Wanis KN, Ardiles V, Alvarez FA, Tun-Abraham ME, Linehan D, de Santibañes E, Hernandez-Alejandro R (2018) Intermediate-term survival and quality of life outcomes in patients with advanced colorectal liver metastases undergoing associating liver partition and portal vein ligation for staged hepatectomy. Surgery 163(4): 691-697

24. Moris D, Ronnekleiv-Kelly S, Kostakis ID, Tsilimigras DI, Beal EW, Papalampros A, Dimitroulis D, Felekouras E, Pawlik TM (2018) Operative results and oncologic outcomes of associating liver partition and portal vein ligation for staged hepatectomy (ALPPS) versus two-stage hepatectomy (TSH) in patients with unresectable colorectal liver metastases: a systematic review and meta-analysis. World J Surg 42(3):806-815

25. Guiu B, Quenet F, Escal L, Bibeau F, Piron L, Rouanet P, Fabre JM, Jacquet E, Denys A, Kotzki PO, Verzilli D, Deshayes E (2017) Extended liver venous deprivation before major hepatectomy induces marked and very rapid increase in future liver remnant function. Eur Radiol 27(8):3343-3352

26. Le Roy B et al (2017) Combined preoperative portal and hepatic vein embolization (Biembolization) to improve liver regeneration before major liver resection: a preliminary report. World J Surg 41(7):1848-1856

27. Hocquelet A, Sotiriadis C, Duran R, Guiu B, Yamaguchi T, Halkic N, Melloul E, Demartines N, Denys A (2018) Preoperative portal vein embolization alone with biliary drainage compared to a combination of simultaneous portal vein, right hepatic vein embolization and biliary drainage in Klatskin tumor. Cardiovasc Intervent Radiol 41(12): 1885-1891

28. Panaro F, Giannone F, Riviere B, Sgarbura O, Cusumano C, Deshayes E, Navarro F, Guiu B, Quenet F (2019) Perioperative impact of liver venous deprivation compared with portal venous embolization in patients undergoing right hepatectomy: preliminary results from the pioneer center. Hepatobiliary Surg Nutr 8(4):329337

29. Kobayashi K, Yamaguchi T, Denys A, Perron L, Halkic N, Demartines N, Melloul E (2020) Liver venous deprivation compared to portal vein embolization to induce hypertrophy of the future liver remnant before major hepatectomy: a single center experience. Surgery 167:917-923

30. Le Roy B et al (2020) Combined biembolization induces higher hypertrophy than portal vein embolization before major liver resection. HPB (Oxford) 22(2):298-305

31. Laurent C, Fernandez B, Marichez A, Adam JP, Papadopoulos P, Lapuyade B, Chiche L (2020) Radiological simultaneous portohepatic vein embolization (RASPE) before major hepatectomy: a better way to optimize liver hypertrophy compared to portal vein embolization. Ann Surg 272(2):199-205

32. Esposito F, Lim C, Lahat E, Shwaartz C, Eshkenazy R, Salloum C, Azoulay D (2019) Combined hepatic and portal vein embolization as preparation for major hepatectomy: a systematic review. HPB (Oxford) 21(9):1099-1106

33. Sandstrom $P$ et al (2018) ALPPS improves resectability compared with conventional two-stage hepatectomy in patients with advanced colorectal liver metastasis: results from a Scandinavian multicenter 
randomized controlled trial (LIGRO trial). Ann Surg 267(5):833840

34. Hasselgren K, Røsok BI, Larsen PN, Sparrelid E, Lindell G, Schultz NA, Bjørnbeth BA, Isaksson B, Larsson AL, Rizell M, Björnsson B, Sandström P (2019) ALPPS improves survival compared with TSH in patients affected of CRLM: survival analysis from the randomized controlled trial LIGRO. Ann Surg Publish Ahead of Print

35. Schadde E, Tsatsaris C, Swiderska-Syn M, Breitenstein S, Urner M, Schimmer R, Booy C, Z'graggen BR, Wenger RH, Spahn DR, Hertl M, Knechtle S, Diehl AM, Schläpfer M, Beck-Schimmer B (2017) Hypoxia of the growing liver accelerates regeneration. Surgery 161(3):666-679

36. Schadde E, Guiu B, Deal R, Kalil J, Arslan B, Tasse J, Olthof PB, Heil J, Schnitzbauer AA, Jakate S, Breitenstein S, Schläpfer M, Beck Schimmer B, Hertl M (2019) Simultaneous hepatic and portal vein ligation induces rapid liver hypertrophy: a study in pigs. Surgery 165(3):525-533

37. Shindoh J, Truty MJ, Aloia TA, Curley SA, Zimmitti G, Huang SY, Mahvash A, Gupta S, Wallace MJ, Vauthey JN (2013) Kinetic growth rate after portal vein embolization predicts posthepatectomy outcomes: toward zero liver-related mortality in patients with colorectal liver metastases and small future liver remnant. J Am Coll Surg 216(2):201-209

38. Imamura H, Shimada R, Kubota M, Matsuyama Y, Nakayama A, Miyagawa SI, Makuuchi M, Kawasaki S (1999) Preoperative portal vein embolization: an audit of 84 patients. Hepatology 29(4):1099 1105

39. Olthof PB, Tomassini F, Huespe PE, Truant S, Pruvot FR, Troisi RI, Castro C, Schadde E, Axelsson R, Sparrelid E, Bennink RJ, Adam R, van Gulik TM, de Santibanes E (2017) Hepatobiliary scintigraphy to evaluate liver function in associating liver partition and portal vein ligation for staged hepatectomy: liver volume overestimates liver function. Surgery 162(4):775-783

40. Olthof PB, Schadde E, van Lienden KP, Heger M, de Bruin K, Verheij J, Bennink RJ, van Gulik TM (2017) Hepatic parenchymal transection increases liver volume but not function after portal vein embolization in rabbits. Surgery 162(4):732-741

Publisher's note Springer Nature remains neutral with regard to jurisdictional claims in published maps and institutional affiliations. 